\title{
Acceso a la justicia electoral en el Estado democrático de derecho
}

Electoral Access to Justice in the Democratic State Law

\section{Flavio Galván Rivera*}

\section{Sumario:}

I. Derecho de acceso a la justicia

II. Principio de legalidad y función jurisdiccional

III. Acción impugnativa y acceso a la justicia

IV. Requisitos de procedibilidad y acceso a la justicia

V. Derecho de acceso a la justicia electoral

VI. Tres propuestas inquietantes: acción de inconstitucionalidad, controversia constitucional y Procuraduría de defensa de los derechos políticos del ciudadano

VII. Bibliografía

* Presidente del Tribunal Electoral del Poder Judicial de la Federación de 2006 a 2007; magistrado de la Sala Superior del mismo Tribunal, de 2006 a 2016; magistrado del Tribunal Federal Electoral, en la Segunda Circunscripción Plurinominal, con sede en la Ciudad de Durango, Durango, de 1990 a 1996. 


\section{Resumen:}

Si el derecho fundamental de acceso a la justicia tiene especial relevancia personal y social, su trascendencia en el contexto del derecho electoral asume particular relevancia porque resulta consustancial al concepto de Estado democrático que necesariamente es $\mathrm{y}$ debe ser de derecho. Por ende, en su parte medular, el presente texto se centra en el derecho de acceso a la justicia electoral, presentando algunos casos emblemáticos en donde la Sala Superior del Tribunal Electoral del Poder Judicial de la Federación ha facilitado, e inclusive ampliado, las hipótesis de procedibilidad de los medios de impugnación y, en consecuencia, el acceso a la justicia para el mayor número de sujetos de derecho electoral. En la parte final del texto, el autor esboza tres propuestas dirigidas a perfeccionar el sistema integral de defensa de los derechos político-electorales de los ciudadanos.

\begin{abstract}
:
If the fundamental right of access to justice is important at the individual and collective levels, such right becomes of special relevance in the context of Electoral Law. This greater significance stems from the very definition of a democratic state, which must be based on the rule of law. Thus, the core of this paper focuses on the right of access to electoral justice by presenting emblematic cases brought to the Superior Electoral Court of the Federal Judicial Branch. In these cases, the court facilitated, and even expanded, the conditions for admissibility in the system of challenges for electoral matters. As a consequence, the court effectively increased access to electoral justice to a greater number of plaintiffs in electoral law procedures. The author concludes by outlining three proposals aimed at improving the protection of citizens' political and electoral rights.
\end{abstract}

Palabras clave: derecho procesal electoral, acceso a la justicia, legitimación procesal, requisitos de procedibilidad, principio de legalidad.

Descriptors: election process law, access to justice, standing, procedural requirements, principle of legality. 


\section{Derecho de acceso a la justicia}

El tema propuesto, claro es, sin el sustantivo que califica a la materia que ahora se ofrece explicar en particular, dada la especificidad y reciente análisis doctrinario del derecho electoral y más aún del derecho procesal electoral, se refiere a uno de los aspectos más importantes de todo Estado de derecho democrático en el mundo contemporáneo, tema jurídico-político del cual Mauro Cappelletti expresa:

Sería oportuno, en este punto, buscar encuadrar el "worldwide movement" - el movimiento mundial de pensamiento y de reforma para el acceso a la justicia - en el panorama más amplio de las grandes tendencias evolutivas del derecho y de la justicia en el mundo contemporáneo... este movimiento constituye, en efecto, el núcleo central de la dimensión "social" del derecho y del Estado moderno, dimensión que, sin embargo, no debe verse aisladamente ya que en realidad se agrega a las otras "dimensiones" que emergen en nuestra época como centrales: me refiero sobre todo a la dimensión "constitucional" y a la "transnacional".

Con relación a la primera parte del título mencionado cabe señalar que entre los estudiosos de tal materia contemporánea, existe la interesante pretensión de diferenciar el específico derecho de "acceso a la justicia" del genérico derecho de "acceso a justicia". 2

Con la primera expresión se quiere hacer referencia al derecho fundamental, constitucional o derecho humano, por ende, de todos los sujetos de derecho, con y sin personalidad jurídica, para ocurrir ante los tribunales del Estado, como órganos de autoridad, imparciales y preestablecidos, cuya función consiste en dirimir conforme a derecho, las controversias de intereses de trascendencia jurídica calificadas por la pretensión de una parte y la resistencia de la otra, en las cuales se ven involucrados, de manera inmediata y directa, por afectar los derechos o deberes de los que son titulares.

1 Cappelletti, Mauro, Dimensiones de la justicia en el mundo contemporáneo (cuatro estudios de derecho comparado), trad. de Héctor Fix Fierro, México, Porrúa, 1993, p. 105.

2 Cfr. Álvarez, Gladys Stella, La mediación y el acceso a justicia, Buenos Aires, Argentina, Rubinzal-Culzoni Editores, 2003, pp. 31-34. 
En cambio, con la expresión "acceso a justicia” se quiere aludir a todas las posibilidades lícitas de solución de las mencionadas controversias de intereses jurídicos, ya por conducto de los tribunales mediante un proceso legal y previamente establecido o bien, por conducto no de los tribunales sino de otros procedimientos, instituciones y personas, esto es, conforme a métodos o sistemas "desjudicializados", 3 alternativos o paralelos - a los jurisdiccionales - para alcanzar el mismo fin, la resolución de los conflictos jurídicos, sea o no mediante la aplicación de las leyes, la jurisprudencia, los usos, la costumbre y la teoría del derecho.

En la aplicación de estos métodos paraprocesales de solución de conflictos, se prefiere recurrir a la conciliación, a la prudencia, al sentido común, a los sentimientos y principios éticos, entre otros recursos, en sustitución de las rígidas reglas del derecho, sustantivo y procesal, así como de la exigencia de elementos de prueba, para generar convicción en el órgano juzgador, unipersonal o colegiado.

Ejemplo de estos métodos o procedimientos "desjudicializados" o alternos son el arbitraje, la mediación y la conciliación.

Si bien el estudio del derecho fundamental de acceso a la justicia, en términos genéricos o abstractos, tiene especial relevancia, por su gran trascendencia en la vida de la humanidad, entendida en todas sus manifestaciones, hasta convertirse en tema de estabilidad o inestabilidad social, jurídica y política de un Estado y por ende, en sustento de seguridad y orden jurídico o en causa de inseguridad y desorden jurídico, económico, político y social en general, ${ }^{4}$ en el contexto del derecho electoral, de manera concreta y en especial, asume particular

3 Es evidente que con la voz “judicializar” sólo se hace referencia a la solución de los conflictos de intereses jurídicos, caracterizados o calificados por la pretensión de una parte y la resistencia de la otra. Esta resolución "tradicional", en un Estado de derecho, es mediante un proceso legalmente previsto, en leyes expedidas con anterioridad al hecho que motiva el juicio o proceso y con la intervención de tribunales previamente establecidos, sean o no del Poder Judicial; lo importante es que se trate de órganos imparciales del Estado, investidos de la facultad jurisdiccional; que actúen como terceros imparciales; como órganos de autoridad, ajenos a la relación sustancial entre actor y demandado.

4 Cfr. Jarquín, Edmundo, Discurso pronunciado con ocasión del Foro Internacional "Acceso a la Justicia y Equidad en América Latina”, en Thompson, José (coord.), Acceso a la justicia y equidad. Estudio en siete países de América Latina, San José, Costa Rica, Banco Interamericano de Desarrollo-Instituto Interamericano de Derechos Humanos, 2000, pp. 11-13. 
relevancia porque resulta consustancial al concepto de Estado democrático que necesariamente es y debe ser de derecho.

Si no existe o no se respeta cabalmente el derecho humano de acceso a la justicia, el Estado de derecho deviene inexistente. Sin derecho real y efectivo de acceso a la justicia el Estado democrático deviene inexistente, no es más que una expresión carente de contenido. Sin este derecho, el Estado democrático de derecho resulta una falacia; tan solo una expresión hueca e insultante de la dignidad humana.

Ahora bien, para unir las dos expresiones mencionadas en el título de este trabajo: "derecho de acceso a la justicia" y "derecho electoral", a fin de generar la unidad propuesta: "derecho de acceso a la justicia electoral", es necesario entender que actualmente el derecho electoral ha cobrado también especial relevancia, no sólo en México o en América Latina, sino en todo el mundo contemporáneo; es necesario comprender que el derecho electoral ahora tiene como objetivo común establecer y perfeccionar el sistema de democracia representativa en todos los Estados del planeta, entendida la democracia no sólo como un sistema de organización política y jurídica, sino fundamentalmente como un sistema de vida, sustentado en el constante y permanente mejoramiento económico, político, social y cultural del pueblo; elemento humano del Estado, causa y fin de esta organización social, titular único y originario de la soberanía, del cual emana todo poder público y en cuyo beneficio se debería instituir y ejercer, permanente e invariablemente, sin mentiras, falsedades, ni simulaciones. ${ }^{5}$

Al exponer un tema tan complejo como es el propuesto "derecho de acceso a la justicia electoral", cabe advertir que se abordarán tan solo algunos casos y supuestos emblemáticos que han ampliado o "flexibilizado" las hipótesis de legitimación activa y pasiva en el derecho procesal electoral, así como otros aspectos de procedibilidad de los medios de impugnación en materia electoral federal.

5 Al respecto se debe recordar la definición de democracia contenida en el artículo 3o., fracción II, inciso $a$, de la Constitución Política de los Estados Unidos Mexicanos, al precisar las características que deben distinguir a la educación que imparta el Estado. En la Ley Suprema de la Federación se establece, con toda claridad, que la democracia debe ser considerada “... no solamente como una estructura jurídica y un régimen político, sino como un sistema de vida fundado en el constante mejoramiento económico, social y cultural del pueblo...”. 


\section{Principio de legalidad ${ }^{6}$ y función jurisdiccional}

Al explicar los principios rectores de la materia electoral, como incuestionable función o actividad del Estado (artículo 41, párrafo segundo, base $\mathrm{V}$, de la Constitución federal) ha quedado precisado que el principio de legalidad es la piedra angular sobre la cual se levanta la actual estructura electoral, sustento indiscutible del sistema democrático mexicano.

La observancia plena y estricta del principio de legalidad, lato sensu, ${ }^{7}$ tiene importancia fundamental en todo Estado de derecho que, en consecuencia, debe ser siempre un Estado democrático, porque el principio de legalidad significa la adecuación de toda conducta, tanto de gobernantes como de gobernados, al sistema jurídico vigente, en toda su estructura normativa jerárquica, en cuya cúspide está la Constitución política y consecuentemente, el principio de supremacía constitucional.

En este orden de ideas, no constituye una exageración, sino un acierto y premisa fundamental aseverar de manera clara y contundente que el de legalidad, lato sensu, es el principio de principios en todo Estado de derecho.

Así explicado, resulta evidente que el principio de legalidad tiene una connotación mucho más amplia que la tradicional garantía constitucional o derecho individual de legalidad, prevista en el párrafo primero del artículo 16 de la Constitución general de la República, ${ }^{8}$

6 Cfr. Galván Rivera, Flavio, Derecho procesal electoral mexicano, 2a. ed., México, Porrúa, 2006, pp. 90 y 91.

También se puede consultar, del mismo autor, el trabajo intitulado "El principio de legalidad en materia electoral", Tendencias contemporáneas del Derecho Electoral en el mundo, Memoria del II Congreso Internacional de Derecho Electoral, México, Cámara de Diputados, LV Legislatura, Instituto Federal Electoral, Tribunal Federal Electoral y UNAM, Instituto de Investigaciones Jurídicas, 1993, pp. 677-701.

7 Para el autor, en su acepción amplia, el principio de legalidad también comprende el principio de constitucionalidad, dada la naturaleza de ley suprema, carta magna o norma de normas, que se atribuye a la Constitución política de todo Estado; por supuesto, no se refiere esta expresión únicamente a la observancia de la ley infraconstitucional.

8 El precepto constitucional en cita expresamente establece que: "Nadie puede ser molestado en su persona, familia, domicilio, papeles o posesiones, sino en virtud de mandamiento escrito de la autoridad competente, que funde y motive la causa legal del procedimiento". 
porque ésta se refiere únicamente a la tutela o protección del individuo frente a la actuación de las autoridades, fundamentalmente al emitir actos de molestia; en cambio, el principio de legalidad electoral abarca toda actuación de las autoridades, electorales y no electorales, e incluso de los ciudadanos, individualmente considerados u organizados en partidos políticos, agrupaciones y todo tipo de organizaciones de naturaleza o fines electorales; de los ciudadanos en general o en su calidad de candidatos a cargos de elección popular; de militantes, simpatizantes o dirigentes de partidos políticos; de observadores electorales o de ciudadanos en cualquier otra circunstancia o calidad político-electoral especial.

Por tanto, es factible afirmar que el principio constitucional de legalidad electoral, supremo principio rector en el ejercicio omnicomprensivo de la función estatal electoral, no significa otra cosa que el estricto cumplimiento de lo previsto en la normativa jurídica vigente, en toda su estructura jerárquica. Es la adecuación o fidelidad a lo establecido en el sistema jurídico vigente, en su integridad; es el respecto al sistema jurídico, en toda actuación de los ciudadanos, asociaciones, agrupaciones y partidos políticos, así como de todas las autoridades, electorales y no electorales, siempre que esa actuación tenga efectos en la materia electoral.

En aplicación estricta del principio de legalidad, resulta incuestionable que toda controversia de intereses, de trascendencia jurídica, que surja en la materia electoral, bien por la actuación de las autoridades, que cause agravio a los ciudadanos, partidos políticos, agrupaciones políticas o a otros sujetos de derecho e incluso por la actuación de los partidos políticos, las coaliciones o los frentes de partidos políticos, que cause agravio a los militantes de un partido o a sus simpatizantes, adherentes, candidatos, precandidatos o cualquier otro sujeto de derecho, con el cual tengan relación jurídica de naturaleza política o política-electoral, se debe someter al conocimiento y determinación de las autoridades electorales, administrativas o jurisdiccionales, locales o federales, según sea el caso particular; sin mengua, por supuesto, de agotar por regla en las hipótesis correspondientes, los procedimientos intrapartidistas de solución de conflictos de intereses jurídicos, establecidos en la normativa partidista expedida previamente.

Al hacer referencia sólo a un apartado del sistema jurídico de solución de conflictos de intereses de trascendencia jurídica, entre partes opuestas o contrapuestas, caracterizadas por la pretensión de una par- 
te y la resistencia de la otra, se torna indispensable exponer el concepto de jurisdicción como actividad del Estado, así como la noción de tribunal, con especial referencia al que tiene competencia en materia electoral.

En síntesis, de la jurisdicción se puede decir que es la función soberana del Estado, realizada por conducto del órgano competente del Estado, caracterizado por ser imparcial y objetivo, que tiene como razón y fin de su existencia el conocimiento y resolución, mediante la aplicación del derecho, de los litigios o conflictos de intereses, de trascendencia jurídica, calificados por la pretensión de una parte y la resistencia de la otra. ${ }^{9}$

Asimismo, del Tribunal Electoral, ${ }^{10}$ desde el punto de vista material, es factible aseverar que es el órgano jurisdiccional del Estado al que compete el cumplimiento de la función pública o estatal consistente en resolver mediante la aplicación del derecho, las controversias de intereses de trascendencia jurídica, emergentes de la actuación de los ciudadanos, organizaciones, agrupaciones y partidos políticos, así como de las autoridades, electorales y no electorales, al participar en forma mediata o inmediata, en los procedimientos político-electorales llevados a cabo con la finalidad de renovar, periódica, libre, auténtica y democráticamente, ${ }^{11}$ en el orden federal, a los depositarios del Poder Ejecutivo y del Poder Legislativo de la Unión, con base en el voto libre, universal, igual, secreto, directo, personal e intransferible, de los ciudadanos. ${ }^{12}$

Cabe destacar que similar situación jurídica prevalece en los estados de la República y en el Distrito Federal, ${ }^{13}$ para la renovación libre,

9 Cfr. Galván Rivera, Flavio, op. cit., pp. 116 y 848.

${ }_{10} \mathrm{Al}$ respecto se debe tener presente lo dispuesto en el artículo 99 de la Constitución Política de los Estados Unidos Mexicanos y su reglamentaria Ley General del Sistema de Medios de Impugnación en Materia Electoral. Ibidem. pp. 116 y 117.

11 En este sentido es importante tener presente que el párrafo segundo del artículo 41, de la Constitución federal, establece expresamente que la renovación de los integrantes de los Poderes Ejecutivo y Legislativo de la Federación se debe llevar a cabo mediante la celebración de elecciones libres, auténticas y periódicas.

12 Las mencionadas características, del voto de los ciudadanos, están previstas en el artículo 41, párrafo segundo, base I, párrafo segundo, de la Constitución General de la República y en el numeral 4, párrafo 2, del Código Federal de Instituciones y Procedimientos Electorales.

13 Es pertinente aclarar que aun cuando se celebran elecciones en el Distrito Federal, como en los estados de la República, no se hace referencia formal a los Poderes Ejecutivo, 
auténtica, periódica y democrática de los correspondientes representantes populares o depositarios del poder público local, por cuyo conducto se ejerce el poder soberano del pueblo.

\section{Acción impugnativa y acceso a la justicia}

El acceso a la justicia es el derecho humano, derecho subjetivo público, constitucional o derecho fundamental, que tiene todo gobernado, que significa la facultad de ocurrir a los órganos jurisdiccionales del Estado, para exigir conforme a derecho, el cumplimiento de los deberes jurídicos previstos a su favor o el respeto y libre ejercicio de los derechos de que es titular el enjuiciante. ${ }^{14}$

El derecho constitucional de los gobernados, individual o colectivamente considerados, ${ }^{15}$ de acceso a la justicia eficaz, es una de las características sine qua non de todo Estado de derecho, que necesaria e ineludiblemente debe ser también un Estado democrático, al cual algunos autores identifican o califican como Estado de derecho democrático o Estado constitucional de derecho democrático, con independencia del orden en que se usen los vocablos.

Esta situación jurídico política implica, por otra parte, la proscripción e incluso la tipificación de la venganza privada como conducta ilícita, cuyo remoto antecedente es la famosa Ley del Talión (ojo por ojo, diente por diente). Ahora, por regla, está prohibida la actuación unilateral, voluntaria y libre de los particulares para exigir, incluso por la fuerza, el respeto de sus derechos, bien para salvaguardar su titularidad o su ejercicio libre e incluso para exigir el cumplimiento de los deberes establecidos a favor de quien ejerce violencia, en contra del que no los cumple, a pesar de estar previsto jurídicamente su deber de cumplirlos.

Legislativo y Judicial local, sino exclusivamente a la existencia de órganos de autoridad u órganos de gobierno. Al respecto es importante la consulta y análisis del artículo 122 de la Constitución federal.

14 Cfr. Moreno Ortiz, Luis Javier, Acceso a la justicia, Santa Fe de Bogotá, Colombia, Academia Colombiana de Jurisprudencia, 2000, pp. 89-99.

15 Cfr. Tamayo Salmorán, Rolando, "Class Action. Una solución al problema de acceso a la justicia”, en Academia Mexicana de Legislación y Jurisprudencia, Estudios Jurídicos en Memoria de Alfonso Noriega Cantú, México, Porrúa, 1991, pp. 461-476. 
Simultáneamente, el Estado democrático de derecho genera para sí el deber jurídico insalvable de establecer los tribunales indispensables, como órganos imparciales del Estado, para prestar el servicio público de resolver, mediante la aplicación justa del derecho, los conflictos de intereses de trascendencia jurídica que surjan entre los gobernados e incluso entre los gobernados y los órganos del Estado mismo e incluso los conflictos jurídicos entre los diversos órganos del Estado.

Así, en el sistema jurídico mexicano, el artículo 17, párrafos primero, segundo y tercero, de la Constitución Política de los Estados Unidos Mexicanos, establece literalmente:

Ninguna persona podrá hacerse justicia por sí misma, ni ejercer violencia para reclamar su derecho.

Toda persona tiene derecho a que se le administre justicia por tribunales que estarán expeditos para impartirla en los plazos y términos que fijen las leyes, emitiendo sus resoluciones de manera pronta, completa e imparcial. Su servicio será gratuito, quedando, en consecuencia, prohibidas las costas judiciales.

Las leyes preverán mecanismos alternativos de solución de controversias. En la materia penal regularán su aplicación, asegurarán la reparación del daño y establecerán los casos en los que se requerirá supervisión judicial.

Por tanto, si los gobernados no se pueden hacer justicia por sí mismos, por propia mano, sino que deben recurrir a los procesos y procedimientos establecidos en el sistema normativo vigente, para lo cual deben existir tribunales del Estado, es decir, órganos de autoridad encargados de llevar a cabo la función jurisdiccional, como servicio público, los cuales han de estar en aptitud y disposición de resolver en forma expedita, completa, imparcial, objetiva y gratuita, mediante la aplicación justa del derecho, los conflictos de intereses jurídicos sometidos a su conocimiento y decisión, resulta indispensable mencionar cuál es la vía para ocurrir a esos órganos jurisdiccionales del Estado, además de destacar la realidad social prevaleciente, relativa al derecho de los gobernados de acceder real y eficazmente a la impartición de justicia.

Los medios, vías o posibilidades para acudir a los tribunales del Estado son los juicios y recursos, constitucional y legalmente establecidos; sin embargo, para promoverlos hace falta un acto fundamental del interesado, al cual por regla se denomina demanda, acto jurídico 
por el que se ejerce una acción, la que en todo Estado de derecho democrático es considerada una facultad o derecho subjetivo público de naturaleza constitucional, un derecho humano o fundamental que tiene o debe tener todo gobernado por el sólo hecho de asumir la calidad jurídica de integrante del elemento humano del Estado, por cuanto hace a las personas físicas, individuales o humanas.

En este orden de ideas, se puede sostener que el derecho de acción, como concepto fundamental del derecho procesal, es el derecho subjetivo público o la facultad constitucional que tiene todo sujeto de derecho, con o sin personalidad jurídica, de ocurrir ante el competente órgano jurisdiccional del Estado a hacer valer la o las pretensiones que tenga en contra de determinado o indeterminado sujeto de derecho, igualmente con o sin personalidad jurídica, con independencia de que le asista o no la razón al demandante, porque ser o no titular del derecho sustantivo en controversia sólo es requisito sine qua non para obtener sentencia favorable, no es requisito para acceder a los órganos estatales de administración de justicia. ${ }^{16}$

No obstante, también es necesario señalar que el ejercicio de este derecho público fundamental no es liso y llano; para poder ocurrir a los tribunales del Estado, el gobernado debe cumplir determinados requisitos y formalidades según lo dispuesto en el ordenamiento jurídico procesal aplicable al caso particular.

Por regla, los requisitos de procedibilidad o presupuestos procesales están vinculados con temas como la legitimación procesal y la legitimación en la causa, es decir, quién puede comparecer a juicio, en defensa del interés propio o del interés de otro y quién es el titular del derecho sustantivo motivo de la controversia. Otro tema insalvable es el del interés jurídico, indispensable para estar en aptitud de promover un juicio o recurso, ya sea por agravio directo o inmediato, resentido en el ámbito de derechos y deberes del demandante, o por agravio indirecto, cuando se ejerce la acción en tutela de un interés difuso, colectivo o de grupo e incluso en defensa del interés público, según sea el caso concreto.

Igualmente, reviste gran trascendencia el tiempo en el cual se ejerce el derecho de acción, dado que por un principio de seguridad jurídica, el derecho a demandar en juicio no puede ser imperecedero. El derecho de hacer valer una pretensión, por conducto de los tri-

16 Cfr. Galván Rivera, Flavio, op. cit., p. 851. 
bunales, no puede ni debe permanecer ilimitadamente en el tiempo; debe existir siempre una acotación cronológica para ejercer la acción procesal, de tal suerte que si ese lapso es rebasado, sin ejercer el derecho de ocurrir a los tribunales, este derecho se pierde, se extingue, por el transcurso del tiempo, sumado a la conducta omisa del gobernado, titular del respectivo derecho sustantivo y procesal. En estas circunstancias, el derecho de acción se extingue por caducidad.

Por otra parte, en los ordenamientos jurídicos procesales por regla, se establecen determinados requisitos de forma y fondo para ocurrir, válida y eficazmente, cuando menos por cuanto hace a estos requisitos de procedibilidad, ante los órganos jurisdiccionales del Estado.

El incumplimiento de alguna de las formalidades sustanciales puede traer como consecuencia, por disposición expresa del mismo ordenamiento procesal aplicable, la inadmisión o desechamiento de la demanda respectiva, que no es otra cosa que la declaración de improcedencia del juicio o recurso promovido y por tanto, la imposibilidad de llevar al tribunal correspondiente el conocimiento y decisión del fondo de una específica controversia de intereses de trascendencia jurídica.

Entre tales formalidades, comúnmente está la de presentar la demanda por escrito, en la cual se debe señalar el nombre del actor, además de requerir la firma autógrafa del promovente, con independencia de que éste sea el mismo actor o de que quien promueva lo haga en representación de otro sujeto de derecho, caso en el cual el promovente debe demostrar, con los adecuados elementos de prueba, que tal representación lo legitima para promover el juicio o recurso respectivo.

De gran trascendencia, en el ejercicio de la acción impugnativa ${ }^{17}$ es la cuidadosa expresión de los conceptos de agravio que en muchas ocasiones está revestida de rigurosos requisitos de forma; más aún

17 En el derecho procesal se alude a la acción impugnativa cuando el medio de defensa de los gobernados se promueve para someter a juicio a la autoridad que ha emitido un acto de molestia, que el enjuiciante considera no está ajustado a derecho; que es contraventor de la normativa jurídica aplicable, sea ésta de orden constitucional o legal e incluso infralegal; ya de naturaleza legislada, autoimpuesta, consuetudinaria o jurisprudencial.

Es claro que en este supuesto el derecho del gobernado, de ocurrir a los tribunales del Estado, no es para demandar a otro gobernado, sino para poner en tela de juicio la actuación de un órgano del mismo Estado, a fin de someter al conocimiento y decisión de un órgano jurisdiccional, también del Estado, la pretensión del actor, en el sentido de revocar, anular o modificar el acto de autoridad controvertido, lo cual significa, obvio es, que el juicio es entre un gobernado y un órgano de autoridad del Estado. 
cuando se promueve un medio de impugnación de los considerados de carácter extraordinario y de estricto derecho, toda vez que el incumplimiento de las formalidades previstas, para la aludida exposición de los conceptos de agravio, puede ser sancionado con la improcedencia del juicio o del recurso respectivo, es decir, con el desechamiento o la inadmisión de la demanda.

Queden los antes mencionados sólo como ejemplo de los presupuestos procesales generalmente establecidos en las leyes adjetivas, debiendo atender en cada caso a lo previsto en el ordenamiento jurídico aplicable, a fin de no incurrir en alguna causal de improcedencia del juicio y por ende, de desechamiento o inadmisión de la demanda.

A diferencia del análisis estrictamente jurídico, incluido el de orden constitucional, que implica el estudio de la acción procesal en particular y de los presupuestos procesales en general, otro es el tema de estudio cuando se hace referencia al eficaz derecho de acceso a la justicia, es decir, a la posibilidad cierta, real, social, efectiva, de que el gobernado pueda ocurrir a los órganos jurisdiccionales del Estado, a solicitar la aplicación del derecho, en defensa de sus derechos subjetivos e intereses personales o incluso en defensa del interés público o de un interés colectivo, difuso, de grupo o de clase, como también puede suceder en la práctica y evidentemente, en la teoría del derecho.

En opinión de algunos autores, el tema de acceso real a la justicia, como un aspecto socio-jurídico, está inmerso ya no sólo en los estudios estrictamente jurídicos, sino en otros menos abstractos, más concretos, tangibles e inmediatos, más humanos, como son los de carácter social, cultural, económico, político, quizá religioso o de cualquier otra naturaleza similar.

Al respecto ha escrito Mauro Cappelletti:

De manera bastante más realista, la perspectiva del acceso a la justicia quiere, en cambio, dar el puesto de honor a la perspectiva del consumidor del derecho y de la justicia: al individuo, a los grupos, a la sociedad en su conjunto, y así, a las necesidades, a los reclamos, a las aspiraciones de los individuos, de los grupos y de la sociedad, y sobre todo a los obstáculos de varia naturaleza - económicos, culturales, psicológicos, etcétera-que se interponen entre el derecho entendido como "producto" y el ciudadano que pretende tener acceso a este "producto". ${ }^{18}$

18 Cappelletti, Mauro, op. cit., pp. 111 y 112. 
La preocupación por el acceso a la justicia es actualmente un tema de ocupación no sólo interinstitucional sino inclusive de carácter interdisciplinario. También en este sentido cabe prestar atención a lo expresado por Mauro Cappelletti, al exponer el tema de "La justicia social" como "Acceso a la justicia" y "La responsabilidad del jurista en nuestra época", al tenor siguiente:

El movimiento de "acceso a la justicia" ha representado, en los últimos decenios, una importante expresión, quizá la más importante, de una transformación radical del pensamiento jurídico y de las reformas normativas e institucionales en un número creciente de países... ya sea en sus aspectos culturales, como movimiento intelectual y de investigación, ya sea en sus principales aspectos prácticos, como movimiento de reforma normativa, institucional y procesal... como una respuesta importante, e incluso la más importante... a la crisis del derecho y de la justicia en nuestra época... expresión fundamental... de aquella que puede definirse como la "dimensión social" de la justicia en el mundo contemporáneo. ${ }^{19}$

Entre esta gran variedad de aspectos cabe mencionar, sólo en vía de ejemplo, el conocimiento o desconocimiento que el interesado o titular del derecho sustantivo pueda tener de la ciencia del derecho y, por tanto, su posible autosuficiencia o la necesidad que de obtener asesoría jurídica profesional para la adecuada defensa de su interés jurídico, con el consecuente deber de pagar los honorarios correspondientes.

Igualmente, cobra especial relevancia saber si quien quiere acceder a la impartición de justicia tiene conocimiento o desconocimiento del idioma español; si sabe no únicamente hablar, sino leer y escribir español y, en su caso, cuáles son las causas de su desconocimiento. Resulta relevante, incluso, conocer cuál es la cercanía o distancia entre el domicilio del gobernado y la sede del tribunal competente para conocer del caso y cuál la facilidad o dificultad para asistir a esa sede.

Así, cobran especial importancia muchos aspectos más, derivados todos de la compleja realidad social e individual de los interesados que trascienden, de manera incuestionable, al real y efectivo derecho de acceso a la impartición de justicia, en general.

$19 \quad$ Ibidem, pp. 81 y 82. 


\section{Requisitos de procedibilidad y acceso a la justicia}

De lo expuesto con antelación y en líneas posteriores, cabe destacar que el derecho fundamental de acceso a la justicia, no obstante su calidad especial de derecho constitucional e incluso de derecho humano, ${ }^{20}$ no exime a su titular del deber jurídico o carga procesal de cumplir, en su oportunidad, los correspondientes presupuestos procesales o requisitos de procedibilidad.

Si el actor, al ejercer su derecho de acción y promover el respectivo juicio o recurso, no cumple los requisitos indispensables para la procedibilidad de ese medio de defensa o de impugnación, el órgano juzgador carecerá de los elementos necesarios para admitir la demanda y dar inicio al proceso correspondiente, lo cual devendría, finalmente, en negativa de acceso a la impartición de justicia por incumplimiento de los presupuestos procesales, de los cuales habló por vez primera Oskar von Bülow ${ }^{21}$ y que Hernando Devis Echandía explica en los términos siguientes:

... para la formación válida de la relación jurídica procesal se requiere, además de la demanda, la denuncia o la querella, que se cumplan ciertos requisitos indispensables para que aquéllas sean atendidas por el juez y le impongan... la obligación de iniciar el proceso. Estos requisitos son conocidos como los presupuestos procesales.

Esos presupuestos determinan el nacimiento válido del proceso...

Por lo tanto, se trata de supuestos previos al proceso o requisitos sin los cuales éste no puede ser iniciado válidamente, y deben, por ello, concu-

20 Es importante tener en mente que el poder revisor permanente de la Constitución, mediante decreto publicado en el Diario Oficial de la Federación el 10 de junio de 2011, modificó el título del Capítulo I del Título Primero de la Constitución Política de los Estados Unidos Mexicanos; sustituyó el título “De las Garantías Individuales” por el "De los Derechos Humanos y sus Garantías”, reconociendo la calidad de derechos constitucionales a los derechos humanos precisados en el capítulo en cita, entre éstos, el derecho de acceso a la justicia.

21 Para el conocimiento de esta teoría se debe consultar la obra del autor en cita, titulada Excepciones y presupuestos procesales; entre otras, cabe citar la edición del Tribunal Superior de Justicia del Distrito Federal, México, de 2001. 
rrir en el momento de formularse la demanda... a fin de que el juez pueda admitirla o iniciar el proceso... ${ }^{22}$

Es incuestionable que para la procedibilidad de los juicios y recursos electorales también se deben satisfacer los requisitos de procedibilidad o presupuestos procesales, previstos fundamentalmente en los artículos 41, párrafo segundo, base VI, y 99, párrafo cuarto, de la Constitución Política de los Estados Unidos Mexicanos, así como en el texto de la Ley General del Sistema de Medios de Impugnación en Materia Electoral y en la parte conducente de la Ley Orgánica del Poder Judicial de la Federación.

Por otra parte, aun cuando sólo como criterio orientador, ya que carece de obligatoriedad en materia electoral, cabe citar la tesis de jurisprudencia, con el rubro y texto siguiente:

Justicia, ACCESO A LA. LA POTESTAD QUE SE OTORGA AL LEGISLADOR EN EL ARTÍ́CULO 17 DE LA CONSTITUCIÓN GENERAL DE LA REPÚBLICA, PARA FIJAR LOS PLAZOS Y TÉRMINOS CONFORME A LOS CUALES AQUÉLLA SE ADMINISTRARÁ NO ES ILIMITADA, POR LO QUE LOS PRESUPUESTOS O REQUISITOS LEGALES QUE SE ESTABLEZCAN PARA OBTENER ANTE UN TRIBUNAL UNA RESOLUCIÓN SOBRE EL FONDO DE LO PEDIDO DEBEN ENCONTRAR JUSTIF ICACIÓn CONSTITUCIONAL.- De la interpretación de lo dispuesto en el artículo 17, párrafo segundo, de la Constitución General de la República se advierte que en ese numeral se garantiza a favor de los gobernados el acceso efectivo a la justicia, derecho fundamental que consiste en la posibilidad de ser parte dentro de un proceso y a promover la actividad jurisdiccional que, una vez cumplidos los respectivos requisitos procesales, permita obtener una decisión en la que se resuelva sobre las pretensiones deducidas, y si bien en ese precepto se deja a la voluntad del legislador establecer los plazos y términos conforme a los cuales se administrará la justicia, debe estimarse que en la regulación respectiva puede limitarse esa prerrogativa fundamental, con el fin de lograr que las instancias de justicia constituyan el mecanismo expedito, eficaz y confiable al que los gobernados acudan para dirimir cualquiera de los conflictos que deriven de las relaciones jurídicas que entablan, siempre y cuando las condiciones o presupuestos procesales que se establezcan encuentren sustento en los diversos prin-

22 Devis Echandía, Hernando, Teoría general del proceso, 3a. ed., Buenos Aires, Universidad, 2004, p. 273. 
cipios o derechos consagrados en la propia Constitución General de la República; por ende, para determinar si en un caso concreto la condición o presupuesto procesal establecidos por el legislador ordinario se apegan a lo dispuesto en la Norma Fundamental deberá tomarse en cuenta, entre otras circunstancias, la naturaleza de la relación jurídica de la que derivan las prerrogativas cuya tutela se solicita y el contexto constitucional en el que ésta se da [El texto destacado con negritas es por el autor de este trabajo]. ${ }^{23}$

Como se puede advertir, la necesidad de cumplir los requisitos de procedibilidad no son privativos de una determinada especie de juicios o recursos, son parte esencial de la teoría general del derecho procesal y por ende, común a todo tipo de proceso, incluidos por supuesto, los juicios y recursos en materia electoral.

\section{Derecho de acceso a la justicia electoral}

Expuestos, de manera sintetizada, temas de tanta relevancia jurídica como el principio de legalidad lato sensu en materia electoral y otros de naturaleza estrictamente procesal, como la acción, la jurisdicción, el proceso y los presupuestos procesales o requisitos de procedibilidad; enfrentados a la realidad social del derecho humano de acceso efectivo a los tribunales del Estado para resolver mediante la aplicación del Derecho, las controversias de intereses de trascendencia jurídica, cualificadas por la pretensión de una parte (demandante) y la resistencia de la otra (demandada o autoridad responsable), resulta oportuno citar ahora, sólo en vía de ejemplo, algunos casos relativos a la actuación y criterios de la Sala Superior del Tribunal Electoral del Poder Judicial de la Federación, para hacer posible el acceso real y eficaz de los justiciables a la impartición de justicia electoral.

A manera de nota explicativa introductoria, cabe recurrir, una vez más, al pensamiento de Mauro Capeletti, quien ha expresado la siguiente reflexión:

${ }^{23}$ Número 33, del Pleno de la Suprema Corte de Justicia de la Nación, t. I, Materia Constitucional, p. 56, del Apéndice (actualización 2001) del Semanario Judicial de la Federación y su Gaceta, Novena Época. 


\begin{abstract}
Si es verdad que la gran revolución cultural de las sociedades democráticas modernas, aunque hasta ahora en gran medida incompleta, es la de la igualdad no meramente formal, será preciso reconocer que el movimiento para el acceso a la justicia representa una de las puntas más avanzadas de esta revolución. Esto ha llevado, en el mundo del derecho, a una nueva perspectiva tal que hace hablar de una "revolución copernicana" en la concepción del derecho. La tradicional concepción "tolemaica" consistía en ver al derecho exclusivamente desde la perspectiva de los "productores” y su producto: el legislador y la ley, la administración pública y el acto administrativo, el juez y la resolución judicial. ${ }^{24}$
\end{abstract}

Conforme a la moderna doctrina jurisdiccional, caracterizada por su naturaleza garantista, tuteladora de los derechos fundamentales del hombre, la Sala Superior del Tribunal Electoral del Poder Judicial de la Federación ha dictado múltiples sentencias y emitido diversos criterios que se distinguen por haber facilitado e inclusive ampliado las hipótesis de procedibilidad de los medios de impugnación y en consecuencia el acceso a la justicia para el mayor número de sujetos de derecho electoral, sin tergiversar con ello la letra de la ley y tampoco la intención del legislador, constitucional o legal.

A manera de ejemplo se citan los siguientes casos:

\title{
1. Legitimación de las autoridades electorales locales para impugnar
}

Al exponer el tema enunciado se propone una nota introductoria, a fin de explicar la existencia de dos especies de legitimación, en el contexto del derecho procesal electoral mexicano, una considerada de naturaleza "ordinaria” y otra calificada como legitimación procesal "extraordinaria".25

24 Cappelletti, Mauro, op. cit., p. 111.

25 Esta clasificación bipartita no existe en la doctrina del derecho procesal electoral, es una propuesta del autor de este trabajo, derivado de la teoría general del derecho procesal y de la experiencia emergente de la práctica cotidiana en la Sala Superior del Tribunal Electoral del Poder Judicial de la Federación, fundamentalmente a partir de la reforma constitucional de noviembre de 2007 y la reforma legal electoral de julio de 2008. 
A. Legitimación ordinaria

Los medios de impugnación en materia electoral pueden ser caracterizados válidamente como los medios de defensa que el legislador ha dado a los gobernados, frente a la actuación de los órganos de autoridad en materia electoral, con la finalidad de controvertir su actuación, a fin de ajustarla a los principios de legalidad, constitucionalidad y definitividad (artículo 41, párrafo segundo, base VI, de la Constitución).

Cabe aclarar que en este ámbito del derecho, no se hace alusión a todo tipo de gobernado sino en principio, única y exclusivamente a los sujetos de derecho que participan en la materia política-electoral, lo cual lleva a pensar sólo en los ciudadanos mexicanos, individualmente considerados o bien organizados en sociedades, asociaciones, agrupaciones o partidos, todos de naturaleza política.

Igualmente se hace alusión a los ciudadanos en general, en algunos casos y en otros, a ciudadanos con una calidad jurídico-política especial, como pueden ser los militantes, simpatizantes o adherentes de un partido político determinado, así como los aspirantes a precandidatos o a candidatos a un cargo de elección popular; también se alude a ciudadanos ya electos como representantes populares e incluso a quienes han tomado o no posesión del cargo y a los que, en calidad de servidores públicos, se les impide u obstaculiza el desempeño de las funciones inherentes al cargo o por el periodo para el cual fueron electos.

También se debe anotar, como un supuesto de legitimación ordinaria, el derecho concedido a los ciudadanos vinculados de manera inmediata y directa con un partido político o una coalición de partidos, a fin de controvertir los actos, resoluciones y procedimientos de los órganos de dirección, del respectivo partido político o coalición, cuando afecten alguno de sus derechos políticos o político-electorales.

Además, en este enunciado, se debe tener presente que a partir de la reforma a la Ley General del Sistema de Medios de Impugnación en Materia Electoral (LGSMIME), según decreto publicado en el Diario Oficial de la Federación el 1o. de julio de 2008, a fin de controvertir las determinaciones del Instituto Federal Electoral, relativas a la imposición de sanciones electorales, se ha legitimado, en términos generales, a toda persona física o moral, nacional o no que se considere agraviada para que pueda promover el respectivo recurso de apelación (artículo 45 , párrafo 1 , inciso $b$, fracción IV, de la LGSMIME). 
En términos de la misma reforma legal, se ha otorgado legitimación a las personas físicas y morales que se ostenten como acreedoras de un partido político nacional en liquidación para que puedan promover el recurso de apelación en contra del Instituto Federal Electoral, con la finalidad de controvertir la resolución de liquidación o los actos del procedimiento de liquidación, "que causen una afectación sustantiva" a la apelante, persona física o moral, nacional o extranjera (artículos 43 Bis y 45, párrafo 1, inciso $c$, fracción II, de la LGSMIME).

A la legitimación brevemente expuesta bien se puede calificar como legitimación ordinaria, en el derecho procesal electoral federal, por tratarse de personas físicas o morales que tienen naturaleza jurídica de gobernadas, es decir, que guardan relaciones de subordinación frente a las autoridades electorales.

\section{B. Legitimación extraordinaria o por excepción}

Si bien es verdad, conforme a lo expuesto, que los medios de impugnación en materia electoral, están previstos a favor de los gobernados, con la finalidad de controvertir actos de autoridad, por regla, y que sólo de manera excepcional son procedentes para cuestionar la validez y juridicidad de los actos de los partidos políticos y de las coaliciones de partidos, también es cierto que de manera extraordinaria, sólo por vía de excepción se debe admitir que los órganos de autoridad electoral, administrativa y jurisdiccional, con o sin personalidad jurídica, están legitimados para promover tales medios de defensa, en especial el recurso de apelación, en contra del Instituto Federal Electoral, a fin de obtener la tutela jurisdiccional y por ende, la eficacia plena de los derechos constitucionales previstos a favor de tales autoridades, específicamente, en materia de acceso a radio y televisión, para el efecto de lograr su publicidad institucional.

Al respecto la Sala Superior del Tribunal Electoral del Poder Judicial de la Federación ha considerado legitimadas, en términos del artículo 17 de la Constitución Política de los Estados Unidos Mexicanos, para promover el recurso de apelación, fundamentalmente conforme a lo previsto en los artículos 40, 45 y 47, de la Ley General del Sistema de Medios de Impugnación en Materia Electoral, a las autoridades electorales locales, administrativas y jurisdiccionales, siempre que se trate de controvertir actos de autoridad emitidos por los órganos del Instituto Federal Electoral, que consideren violatorios de su derecho 
constitucional de acceso a radio y televisión, de acuerdo con lo dispuesto en el artículo 41, párrafo segundo, base III, apartado A, inciso $g$, de la misma carta magna que, en su parte conducente, es al tenor siguiente:

Con independencia de lo dispuesto en los apartados A y B de esta base y fuera de los períodos de precampañas y campañas electorales federales, al Instituto Federal Electoral le será asignado hasta el doce por ciento del tiempo total de que el Estado disponga en radio y televisión, conforme a las leyes y bajo cualquier modalidad; del total asignado, el Instituto distribuirá entre los partidos políticos nacionales en forma igualitaria un cincuenta por ciento; el tiempo restante lo utilizará para fines propios o de otras autoridades electorales, tanto federales como de las entidades federativas...

Para arribar a la conclusión precedente se utilizó como argumento fundamental el mismo que ya existía desde el derecho romano: ser titular de un derecho, que no está protegido con la posibilidad de defenderlo en juicio es tanto como no tenerlo. ${ }^{26}$

Si el respeto o el ejercicio de un auténtico derecho subjetivo, constitucionalmente otorgado a las autoridades electorales de los Estados y del Distrito Federal, tanto administrativas como jurisdiccionales, no puede ser defendido en juicio electoral, resulta tan inútil, tan ineficaz, como el hecho mismo de no tenerlo, con la agravante, en este particular, de hacer nugatorio lo previsto expresamente en el precepto de la ley suprema de la federación, que ha quedado transcrito, en su parte conducente.

En consecuencia, aun cuando las autoridades electorales no estén mencionadas expresamente entre los sujetos legitimados por la Constitución federal y la Ley General del Sistema de Medios de Impugnación en Materia Electoral; aun cuando en apariencia se desnaturalice el sistema de impugnación electoral o que se desvirtúe la finalidad que determinó al legislador a instituir esos medios jurisdiccionales de de-

$26 \mathrm{Al}$ autor de este trabajo correspondió la oportunidad histórica de proponer este criterio al someter, a la consideración del Pleno de la Sala Superior, el proyecto de sentencia correspondiente al recurso de apelación identificado con la clave SUP-RAP-209/2008, promovido por el Tribunal Electoral del Estado de Yucatán, en contra de la Dirección Ejecutiva de Prerrogativas y Partidos Políticos del Instituto Federal Electoral, para impugnar la negativa de otorgarle tiempo en televisión, para su publicidad institucional. 
fensa electoral, lo cierto es que a partir de la reforma al artículo 41 de la Constitución federal, según decreto publicado en el Diario Oficial de la Federación el 13 de noviembre de 2007, las autoridades electorales locales, administrativas y jurisdiccionales, están plenamente legitimadas para demandar en juicio el respeto de su derecho constitucional de acceso a radio y televisión, para fines institucionales.

Esta forma de pensar dio origen a la tesis de jurisprudencia identificada con la clave 19/2009, aprobada por la Sala Superior del Tribunal Electoral del Poder Judicial de la Federación, en sesión pública celebrada el 12 de agosto de 2009, con el rubro y texto siguiente:

Apelación. Las aUtoridades electorales están legitimadas Para IMPUGNAR LA ASIGNACIÓN DE TIEMPO EN RADIO Y TELEVISIÓN.- La interpretación de lo previsto en los artículos 41, párrafo segundo, base III, apartado A, inciso g), de la Constitución Política de los Estados Unidos Mexicanos, y 45 de la Ley General del Sistema de Medios de Impugnación en Materia Electoral, permite concluir que las autoridades electorales, tanto administrativas como jurisdiccionales, al ser titulares del derecho a disponer de tiempo en radio y televisión, también están legitimadas para recurrir en apelación cualquier acto de la autoridad administrativa electoral federal que restrinja o vulnere ese derecho. Así, aun cuando dichas autoridades no están previstas entre los sujetos que pueden promover tal recurso, por ser este medio de impugnación, en general, el procedente para controvertir las resoluciones del Instituto Federal Electoral se les debe reconocer la posibilidad legal de interponerlo. Lo contrario implicaría sostener que por una omisión normativa dichas autoridades no puedan hacer valer ante esta Sala Superior, el derecho a disponer de tiempos en radio y televisión para sus fines propios, en franca contravención a la garantía de acceso a la jurisdicción efectiva prevista en el artículo 17 de la Constitución.

\section{Legitimación de otras personas físicas y morales}

Como ha quedado señalado, los medios de impugnación o de defensa en materia electoral se han establecido, por regla, en beneficio de los ciudadanos, individualmente considerados o bien organizados para participar en la vida política del Estado, ya en partidos políticos, asociaciones, agrupaciones o cualquier otro tipo de organización 
de naturaleza política o con fines políticos, con independencia de su específica naturaleza jurídica y normativa jurídica aplicable. Excepcionalmente, estos medios de defensa han sido previstos en beneficio de los ciudadanos en su calidad específica de candidatos a un cargo de elección popular.

De lo mencionado resulta evidente que los aludidos medios de impugnación son de carácter especializado, no son de naturaleza ordinaria, no han sido establecidos para ser promovidos por la generalidad de los sujetos de derecho, con o sin personalidad jurídica.

No obstante, el derecho electoral mexicano y el derecho procesal electoral contemporáneo se torna más completo y complejo cada día. A la par que cobra mayor presencia e importancia en la realidad política y social, avanza en la sistematización normativa y científica, abarcando temas que no hace mucho tiempo no eran considerados en el contexto de la función estatal electoral y que, por ende, tampoco eran motivo de atención para el legislador y mucho menos, para el juez electoral.

Entre estos temas novedosos están las actividades de las empresas, personas físicas o morales, que tienen por objeto la realización y publicación de encuestas en materia electoral, así como las de aquellas interesadas en comunicar a la sociedad los mensajes de los aspirantes a candidatos a cargos de elección popular, de los candidatos mismos y de los partidos políticos o coaliciones de partidos, antes y durante el tiempo en que se llevan a cabo las campañas y precampañas correspondientes.

Por esta razón, los jueces y tribunales electorales deben estar dispuestos no sólo a interpretar las leyes vigentes con espíritu garantista y tutelador de los derechos humanos, sino también a integrar la normativa vigente, con esas características, a fin de hacer posible el acceso eficaz a la justicia electoral, en beneficio de todas las personas, físicas y morales e incluso de los sujetos de derecho sin personalidad jurídica, que resientan algún agravio por la actuación de los órganos de autoridad, de los partidos políticos o de las coaliciones de partidos.

La apertura de criterio que se propone es con el único objetivo de salvaguardar los derechos de los interesados que demandan justicia; sin que sea obstáculo para permitirles el acceso a los tribunales del Estado, mediante la promoción de juicios y recursos electorales que en el texto y contexto de la legislación electoral en vigor no estén previstos los supuestos de procedibilidad exactamente aplicables, a los casos 
concretos que se controvierten, siempre que en el ejercicio prudente, razonable y racional de las facultades otorgadas a los jueces electorales se arribe a la conclusión de que el incoado medio de defensa electoral debe ser conocido con tal naturaleza jurídica, al quedar ubicado en el ámbito de atribuciones de los órganos jurisdiccionales de esta materia especializada, por la naturaleza y consecuencias jurídicas de la litis planteada en el particular.

Aun cuando parezca verdad de Perogrullo, cabe recordar que en el ejercicio de sus facultades, es evidente que los jueces electorales, como todos los demás juzgadores, deben ser y actuar no sólo como jurisperitos, sino sobre todo y fundamentalmente, como jurisprudentes.

\section{Derecho a ser votado, en su vertiente de derecho a permanecer en el cargo $^{27}$}

La posibilidad de impugnar actos que atenten contra la permanencia de los representantes populares en el desempeño del cargo, para el cual fueron electos, es actualmente un tema en estudio, discusión y reflexión, a partir de la premisa de que el derecho a ser votado no se agota con la posibilidad de ser designado candidato para contender en una elección popular; abarca también el derecho a ser proclamado candidato electo o triunfador, si se obtiene válidamente el mayor número de votos, emitidos por los ciudadanos; implica también el derecho de acceder al desempeño del cargo, para el cual ha sido electo y, en opinión del suscrito, también incluye el derecho a permanecer en el cumplimiento de las funciones inherentes al cargo, por todo el periodo previsto en la legislación aplicable, a menos que exista causa jurídicamente justificada para la separación respectiva, lo cual debe quedar debidamente acreditado en juicio, para el caso de controversia. ${ }^{28}$

27 Este criterio ha sido sostenido por la Sala Superior, al emitir sentencia en los juicios para la protección de los derechos político-electorales del ciudadano identificados con las claves de expediente SUP-JDC-79/2008 (Pijijiapan, estado de Chiapas, en el cual el autor de este trabajo fue ponente, cuyo proyecto de sentencia fue aprobado por unanimidad de votos) y SUP-JDC-1120/2009 (Villa Zaachila, estado de Oaxaca, en el cual el suscrito fue encargado del engrose de sentencia, aprobado por mayoría de 5 votos).

28 Este tesis, ahora sustentada por la Sala Superior del Tribunal Electoral del Poder Judicial de la Federación, fue propuesta originalmente por el autor de este trabajo, al emitir voto particular, en contra del criterio de la mayoría del colegiado en cita, al dictar sen- 


\section{Suplencia total de la queja para el caso de demandantes indígenas}

Para determinar la procedibilidad del juicio para la protección de los derechos político-electorales del ciudadano, cuando es promovido por integrantes de comunidades o pueblos indígenas, juicio en el que se controvierta el posible menoscabo de la autonomía política de la comunidad o de los derechos individuales de naturaleza político-electoral de alguno o algunos de sus integrantes, todo ello en el contexto del vigente sistema electoral por usos y costumbres, ${ }^{29}$ se ha asumido el criterio de que la autoridad jurisdiccional electoral debe no sólo suplir la deficiencia en la expresión de los conceptos de agravio, sino incluso llegar a la denominada, por la Sala Superior del Tribunal Electoral, "suplencia total" a fin de garantizar el acceso eficaz a la justicia electoral, así como la eficacia plena de los derechos político-electorales de los integrantes de las comunidades indígenas.

El criterio reiterado de la Sala Superior, al resolver asuntos similares de su competencia, la llevó a constituir la tesis de jurisprudencia identificada con la clave 13/2008, aprobada en sesión pública celebrada el primero de octubre de 2008, con el rubro y texto siguientes:

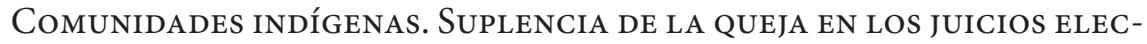
TORALES PROMOVIDOS POR SUS INTEGRANTES.- La interpretación sistemática y funcional de los artículos 2, apartado A, fracción VIII, 17 y 133 de la Constitución Política de los Estados Unidos Mexicanos; 23, apartado 1, de la Ley General del Sistema de Medios de Impugnación en Materia Electoral; 2, 4, 9, 14 y 15 de la Ley Federal para Prevenir y Eliminar la Discriminación; 2, 4, apartado 1 y 12 del Convenio 169 de la Organización Internacional del Trabajo sobre Pueblos Indígenas y Tribales en Países Independientes y 1, apartado 1, de la Convención Americana sobre Derechos Humanos, conduce a sostener que en el juicio para la protección de

tencia en el juicio para la protección de los derechos político-electorales del ciudadano identificado con la clave de expediente SUP-JDC-25/2010, incoado por Jaime Sánchez Rodríguez, en contra del presidente municipal del Ayuntamiento de Rayón, Chiapas y otras autoridades del municipio.

29 El régimen jurídico sustentado en usos y costumbres o derecho consuetudinario, aplicable a las comunidades indígenas, en materia político-electoral, está previsto en el artículo 2o., apartado A, fracción III, de la Constitución Política de los Estados Unidos Mexicanos. 


\begin{abstract}
los derechos político-electorales del ciudadano promovido por integrantes de comunidades o pueblos indígenas, en el que se plantee el menoscabo de su autonomía política o de los derechos de sus integrantes para elegir sus autoridades o representantes, conforme a sus propias normas, procedimientos y prácticas tradicionales, la autoridad jurisdiccional electoral debe no sólo suplir la deficiencia de los motivos de agravio, sino también su ausencia total y precisar el acto que realmente les afecta, sin más limitaciones que las derivadas de los principios de congruencia y contradicción, inherentes a todo proceso jurisdiccional, porque tal suplencia es consecuente con los postulados constitucionales que reconocen los derechos de estos pueblos o comunidades y sus integrantes. Lo anterior, porque el derecho fundamental a la tutela jurisdiccional efectiva, prevista en el artículo 17 constitucional, tiene como presupuesto necesario la facilidad de acceso a los tribunales. Esto es así, porque el alcance de la suplencia de la queja obedece al espíritu garantista y antiformalista, tendente a superar las desventajas procesales en que se encuentran, por sus circunstancias culturales, económicas o sociales.
\end{abstract}

\title{
VI. Tres propuestas inquietantes: acción de inconstitucionalidad, controversias constitucionales y procuraduría de defensa del ciudadano
}

\section{Acción de inconstitucionalidad}

A fin de tener un sistema integral de defensa de los derechos políticoelectorales de los ciudadanos, individualmente considerados u organizados en forma distinta a la integración de partidos políticos, se debe ampliar la legitimación para ejercer la acción de inconstitucionalidad, a fin de controvertir leyes electorales, federales y locales que se opongan a lo dispuesto en la Ley Suprema de la Federación, según lo previsto en el artículo 105, fracción II, inciso $f$, de la Constitución federal, concediendo el derecho de impugnación no sólo a los partidos políticos, nacionales y locales, según el caso, sino también a los ciudadanos, a las agrupaciones políticas y a cualquier otra forma de organización de los ciudadanos, siempre que tenga fines político-electorales, con lo cual se lograría un mejor acceso a la justicia electoral. 


\section{Controversias constitucionales}

También en este renglón es importante hacer algunas reformas al artículo 105, fracción I, de la Constitución Política de los Estados Unidos Mexicanos, a fin de derogar la prohibición aún vigente de la procedibilidad de las controversias constitucionales en materia electoral; resulta ser una necesidad urgente de superar, el establecimiento del correlativo supuesto de procedibilidad, para el caso de conflicto de facultades entre las autoridades electorales, federales y locales, de unos contra los otros, además de preveer la procedibilidad de este tipo de controversias constitucionales electorales entre los órganos de autoridad electoral y los demás órganos de autoridad, administrativa, legislativa y jurisdiccional, tanto federales como locales e incluso municipales.

Por el momento quede hecha la propuesta, para ser desarrollada con mayor detalle en otra oportunidad.

\section{Procuraduría de defensa de los derechos políticos del ciudadano}

Tema de especial trascendencia es la defensa de los derechos políticos, en general, y de los derechos político-electorales, en particular, de todos los ciudadanos, frente a los órganos de autoridad del Estado y frente a los órganos de decisión o de dirección de los partidos políticos, individualmente considerados o vinculados entre sí mediante convenios de actuación conjunta, como son los frentes y las coaliciones de partidos.

El ciudadano, en general, debe ser defendido por el Estado, para el ejercicio y exigencia de respeto de sus derechos, prerrogativas y deberes políticos y político-electorales, como una forma de ejercer el derecho de acceso eficaz a la justicia electoral.

Sin la adecuada y oportuna asesoría jurídica, en múltiples ocasiones y circunstancias, resulta sumamente compleja la defensa de los derechos del ciudadano común, lo cual ha de redundar en agravio de éste y seguramente, en un desgaste injustificado e injustificable del sistema democrático mexicano e incluso en deterioro de la imagen y de la existencia misma del Estado democrático de derecho que México preconiza ser en todos los confines del planeta y que el pueblo merece 
tener, en congruencia con su historia y lo dispuesto principalmente en los artículos 35, 36, 39, 40 y 41 de la Constitución federal.

\section{Bibliografía}

Álvarez, Gladys Stella, La mediación y el acceso a justicia, Buenos Aires, Rubinzal-Culzoni Editores, 2003.

Cappelletti, Mauro, Dimensiones de la justicia en el mundo contemporáneo (cuatro estudios de derecho comparado), trad. de Héctor Fix Fierro, México, Porrúa, 1993.

Devis Echandía, Hernando, Teoría general del proceso, 3a. ed., Buenos Aires, Argentina, Editorial Universidad, 2004.

Galván Rivera, Flavio, Derecho procesal electoral mexicano, 2a. ed., México, Porrúa, 2006.

- - - "El principio de legalidad en materia electoral", Tendencias contemporáneas del derecho electoral en el mundo, Memoria del II Congreso Internacional de Derecho Electoral, México, Cámara de Diputados, LV Legislatura, Instituto Federal Electoral, Tribunal Federal Electoral y UNAM, Instituto de Investigaciones Jurídicas, 1993.

JARQuín, Edmundo, Discurso pronunciado con ocasión del Foro Internacional "Acceso a la Justicia y Equidad en América Latina", en Thompson, José (coord.), Acceso a la Justicia y Equidad. Estudio en siete países de América Latina, San José, Costa Rica, Banco Interamericano de Desarrollo-Instituto Interamericano de Derechos $\mathrm{Hu}$ manos, 2000.

Moreno Ortiz, Luis Javier, Acceso a la justicia, Santa Fe de Bogotá, Ediciones Academia Colombiana de Jurisprudencia, 2000.

Tamayo y Salmorán, Rolando, "Class Action. Una solución al problema de acceso a la Justicia”, en Academia Mexicana de Legislación y Jurisprudencia, Estudios jurídicos en memoria de Alfonso Noriega Cantú, México, Porrúa, 1991. 